PETER KRIEGER

\title{
Las primeras dos décadas de los Anales del Instituto de Investigaciones Estéticas: la era de Manuel Toussaint
}

\footnotetext{
Cegún un axioma del famoso historiador Jacob Burckhardt, todas las preguntas que se plantean a la historia surgen de un interés actual. En este sentido, me propongo revisar los inicios intelectuales de nuestra revista, sus intenciones y logros. Al festejarse los 75 años del Instituto de Investigaciones Estéticas (IIE) en 20IO, el interés académico se centra también en su órgano de difusión, los Anales, que desde la perspectiva evaluadora actual ha establecido una firme posición en los discursos sobre las artes, no sólo en México. Una lectura exhaustiva de los primeros 25 números — ahora disponibles en forma digitalizada en la página web del IIE - revela, a mi parecer, una riqueza intelectual enorme, que persiste aunque muchos contenidos de los artículos publicados hayan sido revisados y superados por la investigación actual, en un proceso común para una disciplina vital constantemente renovada. Pero la empresa intelectual y difusiva de Anales mantiene su vigencia, y en las siguientes líneas perfilo algunos de los tópicos tratados en esa publicación, interesantes también para los lectores de hoy. Será un primer y muy breve acercamiento a la propia historia de la revista, que requiere estudios más extensos y profundos, tal vez como tesis de doctorado u otros formatos de investigación.

Anales se relaciona de modo muy estrecho con la fundación misma del IIE, que en 1935 "nació pobremente, pero de noble abolengo, pues fue apadrinado por el Laboratorio de Arte de la Universidad de Sevilla, cuya benemérita
} 
labor es reconocida en el mundo entero". ${ }^{\mathrm{I}}$ Esta cita proviene del número I3 de Anales, en que se celebraba la primera década del Instituto. Según las crónicas elaboradas por la doctora Clementina Díaz y de Ovando ${ }^{2}$ y la doctora Elisa Vargaslugo, ${ }^{3}$ aquel "laboratorio" sevillano, fundado por Francisco Murillo, sirvió como modelo para profesionalizar los estudios sobre las artes en México. Durante una estancia de investigación realizada en 1934, el estudioso sevillano Diego Angulo Íñiguez propuso a sus colegas mexicanos —en primer lugar a Manuel Toussaint - que se fomentara la historiografía del arte en el país por medio de un instituto. Esa iniciativa trajo a la memoria un exhorto emitido por Justo Sierra en septiembre de I9Io, al leer un discurso inaugural de cursos en la Universidad y explicar la meta de ésta: "proteger [lo] que tenemos por indispensable en la cultura nacional -me refiero a las enseñanzas estéticas" ${ }^{4}$ Toussaint recordaría luego ese postulado cuando solicitó al entonces rector de la UNAM, en una carta del 20 de diciembre de 1934, que fundara el Laboratorio de Arte, petición a la que las autoridades respondieron afirmativamente en febrero de 1935. Un año y medio después, el Laboratorio de Arte, que entonces no era sino una pobre "filial del Instituto de Historia", se convirtió, por disposición de un nuevo rector, en el Instituto de Investigaciones Estéticas. Su primer director, el poeta Rafael López, permaneció sólo tres años en el puesto y en febrero de 1939 lo cedió al investigador que ya había dirigido el laboratorio: Manuel Toussaint, figura clave del Instituto y su revista.

Ya en 1937, promovida por el entonces secretario del Instituto, Manuel Moreno Sánchez, se fundó Anales. Pero antes de referir sus contenidos y las estrategias editoriales conviene recapitular sobre los inicios de la publicación y del establecimiento que la ha producido.

Desde siempre, el Instituto se integró a las redes académicas internacionales, en los primeros años por razones históricas y por la fácil comunicación con

I. Anales del Instituto de Investigaciones Estéticas, México, Universidad Nacional Autónoma de México-Instituto de Investigaciones Estéticas [en las siguientes notas abreviado como Anales], vol. IV, núm. I3, I945, p. I.

2. Clementina Díaz y de Ovando, "Manuel Toussaint, historiador", Anales, vol. VI, núm. 25, I957, pp. I03-III.

3. Elisa Vargaslugo, "Aportaciones al estudio del arte colonial iberoamericano", ponencia presentada en la Universidad de Sevilla durante la celebración del centenario del Laboratorio de Arte de esta casa de estudios (texto inédito, 2008).

4. "XXV aniversario del Instituto de Investigaciones Estéticas", Anales, vol. VIII, núm. 30, 1961, p. 5 . 
España -más tarde reemplazada sucesivamente por la establecida con Francia y en especial con Estados Unidos. Anales refleja siempre esa integración a la comunidad académica internacional, que cumple una importante función correctiva de los nacionalismos unidimensionales implícitos en muchos estudios sobre el arte.

Otro aspecto importante es el nombre primigenio, aparentemente científico, de una disciplina adscrita a las humanidades, pues en aquel momento, en España, llamar "laboratorio" a una institución dedicada al estudio del arte garantizó la dotación de mayores fondos para las investigaciones "estéticas", que muchos científicos y economistas ven como ornamento innecesario, prescindible en una casa de estudios. Ese aspecto cobra mucha importancia en la actualidad, cuando muchas universidades del mundo intentan reprimir la creatividad y recortar el sustento de las humanidades, obligándolas a subordinarse a los parámetros de las ciencias - aunque en la UNAM y en los rankings internacionales (especialmente en el Times londinense) son disciplinas sólidas, hay en efecto una innegable pretensión de legitimar los estudios estéticos y de aplicar a quienes las practican evaluaciones (como el SNI) con categorías científicas inadecuadas para las aportaciones de las humanidades. En los años recientes, Anales ha retomado esos debates, en un contexto de revisiones conceptuales que tienden a convertir la historia del arte en ciencia de las imágenes.

Cabe mencionar también que nuestra disciplina comprueba su utilidad social, basada en la libertad académica, gracias a sus investigaciones e iniciativas sobre la preservación de la herencia cultural. Ya en uno de sus primeros números, ${ }^{5}$ Anales denuncia la destrucción de la auténtica arquitectura virreinal de Cuernavaca y la febril y anodina construcción de hoteles cuyos arquitectos y dueños exhiben su desconocimiento de la cultura mexicana — tema de gran actualidad, que, por ejemplo, se aborda en algunos artículos del núm. 85 de Anales correspondiente al otońo de 2004.

La revista Anales comunica los avances de las investigaciones estéticas en México a una comunidad nacional e internacional interesada en las artes y la cultura. Por muchas décadas, esa publicación sirvió también, de manera específica, como foro para promover los proyectos de investigación de los miembros del Instituto. Se publicaban ahí los "informes de actividades de los investigadores", artículos inéditos sobre temas inexplorados y, en muchos casos, avances de libros en proceso. Sin embargo, a partir de la nueva época de Anales cuando Rita Eder

5. "Libros y notas", Anales, vol. I, núm. I, I937, pp. 62 y 63. 
dirigió el Instituto, en la década de los noventa, la revista mudó gradualmente su carácter para convertirse en una publicación internacional especializada, donde todos los textos se sometían a dictámenes académicos rigurosos - los informes de los investigadores, mientras tanto, desaparecen en el nirvana burocrático digital de la Coordinación de Humanidades, y las noticias sobre las múltiples actividades de la planta del Instituto se difunden entonces en el boletín en línea Imágenes.

En todas las décadas de la existencia de Anales continúa la meta (entre paréntesis: evito la palabra teológica "misión", tan de moda en el mundo administrativo neoliberal) de profesionalizar y actualizar los estudios sobre la cultura plástica, musical y literaria. En los años treinta, cuando la historia del arte apenas se perfilaba como disciplina universitaria en México, Toussaint se desenvolvió durante más de 16 años como director del IIE, y reclamó tal profesionalización con palabras que hasta la fecha mantienen vigencia:

En nuestro raquítico medio literario, la crítica no existe. Los autores de libros tienen que contentarse, y lo hacen gustosos, con dos o tres notas elogiosas que publican los amigos periodistas a quienes han regalado sendos ejemplares de su obra. Crítica razonada, que justifique los elogios y las censuras, cuando alguien se atreve a censurar, no debe buscarse. De ahí que casi todos los libros sean tomados como buenos aunque uno afirme lo que otro, precisamente, niega.

Por lo que toca a la Historia del Arte, la cosa resulta peor: todo el mundo escribe sobre ese tema y hay cada artículo de revista, ¡que nos deja fríos de espanto! El público los lee, o mira las ilustraciones al menos, pero nunca se da cuenta de las ruedas de molino con que ha sido obligado a comulgar. ${ }^{6}$

Afortunadamente, la producción intelectual del IIE y su revista académica comprueban que nuestra disciplina se estableció como referencia indispensable y sólida para la comprensión de todos los fenómenos artísticos. No obstante, subsisten algunos problemas expuestos en la cita de Toussaint. Todavía hay, y no sólo en México, cierto incesto entre los autores y los críticos, y los llamados coffee table books sobre arte, con un mínimo de texto entre una abundancia de imágenes opulentas que hace difícil la difusión de los verdaderos avances de

6. Manuel Toussaint, "La Catedral de México. Sus cronistas más recientes", Anales, vol. I, núm. 3, I939, p. 5; sobre los inicios de la historia del arte en México a partir de Bernardo Couto (I872) y Revilla (I902), véase Manuel Toussaint, "Veinte años de investigaciones estéticas", Anales, vol. VI, núm. 22, I954, p. 5. 
investigación estética en los libros académicos, donde justamente se deconstruyen muchos mitos y anacrónicas interpretaciones falsas de los artistas y sus obras.

En este sentido, también Anales tiene que luchar por ganar la atención adecuada dentro del círculo de lectores interesados en el arte, porque en un plano superficial, al echar una primera ojeada a la portada, Anales, con su diseño austero, serio, no tiene el atractivo de una revista con fotos brillantes como Artes de México, Arqueología Mexicana u otros órganos de difusión de las artes. Dentro del esquema neoliberal, en el ambiente cultural es cada vez más difícil mantener revistas de alta calidad académica, donde revisiones y dictaminaciones críticas realizadas por expertos excluyen los estereotipos simples, las trivialidades biográficas y las comercializaciones vulgares del arte.

¿Cómo, entonces, se perfila el carácter intelectual, específico, de Anales, especialmente en la época que nos corresponde revisar en este breve texto, de los años treinta a los cincuenta?

El editorial del primer número, de 1937, escrito por el director del IIE, el poeta Rafael López, anuncia que se investiga y difunde la "fisionomía cultural de México" para promover el "conocimiento de lo nuestro". Ese concepto de corte nacionalista, que se presta a muchos malentendidos y abusos ideológicos, como lo ha explicado Renato González Mello en una indagación puntual, ${ }^{7}$ no impide que en la misma configuración de los siguientes números se incluyeran artículos, noticias y reseńas sobre las artes en el extranjero. Así, la predominante fijación temática en el arte mexicano se ve enriquecida por textos sobre la estampa japonesa, sobre la arquitectura de Guatemala, Perú y Brasil, e incluso sobre el arte danés. ${ }^{8}$ Hay una tendencia a entretejer la investigación sobre el arte mexicano y el ámbito internacional hacia la utopía de una World Art History, promovida actualmente por el Comité Internacional de Historia del Arte (СІна).

7. Renato González Mello, "Culturas del canon, culturas del paradigma“, en Coloquio Internacional de Arte e Historia en Memoria de Juana Gutiérrez Haces (1948-2007). Amans Artis, Amans Veritatis, Gustavo Curiel (ed.), México, Universidad Nacional Autónoma de MéxicoInstituto de Investigaciones Estéticas/Facultad de Filosofía y Letras/Fomento Cultural Banamex (en prensa).

8. Sobre los ejemplos de los temas internacionales, véase Salvador Toscano, "La escultura colonial en Guatemala", Anales, vol. II, núm. 5, I940, pp. 45-53; Manuel Toussaint, "El arquitecto de la Catedral de Cuzco, Perú”, Anales, vol. II, núm. 7, I94I, pp. 59-63; Justino Fernández, "Cándido Portinari. Un gran pintor brasileño", Anales, vol. III, núm. 9, I942, pp. 27-32, y "La ciudad vieja de Aarhus, Dinamarca”, Anales, vol. V, núm. I8, I950, pp. 95-96. 
Los textos acumulados en Anales reflejan las áreas estudiadas y a las (relativamente pocas) personas adscritas al IIE en el pasado. Concretamente, éstas tratan la pintura, la escultura, la arquitectura y el urbanismo, y también la música, la literatura y las artes escénicas, en el marco de las épocas denominadas "prehispánica", "colonial", "siglo xix" y "siglo xx", e incluso publican escritos sobre la sociología y la psicología del arte. Y, desde el inicio, Anales, como revista dedicada a la historia de las artes, no excluye la producción plástica contemporánea, y de esa manera cumple también la función de un órgano especializado en crítica de arte. Ejemplo de ese último aspecto lo constituyen los estimulantes textos de Justino Fernández — posteriormente director del Instituto- sobre José Clemente Orozco. ${ }^{9}$

Sin embargo, hojeando los Anales de las primeras dos décadas, predominan los estudios del arte colonial, escritos con gran entusiasmo y erudición por el "triunvirato" del IIE en esa época: Manuel Toussaint, Francisco de la Maza y Justino Fernández. Paso por paso se incorporaron los nuevos miembros femeninos con sus artículos en los Anales: Clementina Díaz y de Ovando sobre la literatura mexicana popular, ${ }^{\mathrm{IO}} \mathrm{Ida}$ Rodríguez Prampolini sobre el arte indígena y los cronistas de la Nueva España, ${ }^{\text {II }}$ y la joven doctora Elisa Vargaslugo, que presenta una investigación sobre la vicaría de Aculco, ${ }^{\mathrm{I2}}$ notable porque lo ilustran ampliamente fotografías de calidad profesional. Cabe mencionar que esa innovación en la estrategia visual de la revista se basó en el trabajo fundador de la doctora Vargaslugo en la Fototeca del IIE, a partir de 1953.

Invitados especiales de otras disciplinas, como Edmundo O'Gorman, y de otros países, como el estadounidense George Kubler y el alemán Heinrich Berlin, ${ }^{13}$ abren el panorama intelectual de la publicación. Incluso, a partir del número 4 se toma la decisión editorial de incluir en ella también textos en inglés, práctica que se prolonga hasta la fecha.

9. Justino Fernández, "De una charla con José Clemente Orozco", Anales, vol. II, núm. 5, I940, pp. II-I5; "Orozco. El pintor de nuestro tiempo", Anales, vol. IV, núm. I6, I948, pp. 27-4I, y "La trascendencia en la obra de Orozco", Anales, vol. V, núm. I8, I950, pp. 19-26.

ı. Clementina Díaz y de Ovando, "Agua, viento, fuego y tierra en el Romancero Español", Anales, vol. III, núm. I I, I944, pp. 59-83.

I I. Ida Rodríguez Prampolini, "El arte indígena y los cronistas de Nueva España”, Anales, vol. V, núm. I7, I949, pp. 5-I6.

I 2. Elisa Vargaslugo, "La vicaría de Aculco", Anales, vol. VI, núm. 22, I954, pp. I03-I I 4.

I3. Edmundo O'Gorman colabora en Anales a partir del vol. I, núm. 4, 1939, pp. 30-36; el primer texto publicado en inglés fue de George Kubler, "Ucareo and the Escorial”, vol. II, núm. 8, I942, pp. 5-I2. Otro ejemplo de los autores extranjeros es Heinrich Berlin, "Artífices de la Catedral de México", Anales, vol. III, núm. II, 1944, pp. 19-39. 
Más allá de los artículos de investigación, aparecen muchos documentos útiles para el estudio de la historia del arte, a partir del número 6, en el rubro "Informaciones y documentos", equivalente a la sección actual titulada "Obras, noticias, documentos". Sobresalen las muchas reseñas de exposiciones de arte, que indican, a partir del número I2, de 1944, una tendencia a la apertura internacional en las políticas culturales de México.

El lapso de la revista Anales revisado aquí se cierra con la muerte del fundador Manuel Toussaint, ocurrida en noviembre de 1955 en Nueva York, a su regreso de un Congreso Internacional de Historia del Arte celebrado en Venecia, donde por primera vez se incluyó, por iniciativa del mismo Toussaint, el arte latinoamericano. El número 24 de la publicación anuncia su trágica muerte y la intención de dedicar un número monográfico a su memoria. ${ }^{14}$

Sería tema de otro artículo la época en que Justino Fernández dirigió el IIE a partir de agosto de 1956. Poco antes, en el número 22 de Anales, los editores llegaron a un balance positivo: "El éxito que han obtenido estos Anales en el mundo entero se manifiesta por la enorme cantidad de solicitudes que ha habido de ellos en diversas universidades y centros de cultura artística". ${ }^{\text {Is }}$

En tiempos actuales, determinados por la comunicación académico-científica vía internet, ese éxito es medible precisamente porque es posible rastrear las consultas de la versión digitalizada de Anales, que se publican paralelamente a la versión en papel. ${ }^{16}$ Sorprenden las consultas de casi todas partes del mundo, y eso refleja una tendencia irrefrenable a disolver los tradicionales centros del poder discursivo, como la vieja Europa y los Estados Unidos, y a disfrutar la diversidad y el libre intercambio de ideas en el campo de las investigaciones estéticas.

Hay, sin embargo, cierta incertidumbre sobre el término utilizado para referirse a los estudios difundidos en Anales: investigaciones "estéticas". En su número I, la revista empieza con una reflexión conceptual sobre "¿Qué es la Estética?” ${ }^{77}$ De ahí surge una posición axiológica y atemporal, que hoy nada más cultivan los filósofos, y no los historiadores del arte. Comprueba ese artículo que la tarea consiste en "buscar lo permanente en medio de los cambios del arte, los

I4. Con los textos de Justino Fernández, "Manuel Toussaint y Ritter (I890-I955)", Anales, vol. VI, núm. 24, I956, pp. 5-7, y "El pensamiento estético de Manuel Toussaint”, Anales, vol. VI, núm. 25, 1957, pp. 7-19, y Elisa Vargaslugo, "Manuel Toussaint y la pintura colonial", Anales, vol. VI, núm. 25, I957, pp. 47-58.

I 5. Toussaint, "Veinte ańos...", op. cit., p. 7.

I6. Véase www.analesiie.unam.mx.

I7. Samuel Ramos, “¿Qué es la Estética?”, Anales, vol. I, núm. 2, I938, pp. I-5. 
medios, los lugares, hasta encontrar su esencia intemporal; [se] debe perseguir el elemento ahistórico en el medio de la fluyencia histórica del arte”. Esa posición, marcada por Wilhelm Worringer y otros pensadores del expresionismo a inicios del siglo Xx, hoy ha sido rebasada por una concepción de la historia del arte como historia cultural que investiga las funciones específicas de imágenes, letras y sonidos en los procesos sociales. Aunque la etiqueta "investigaciones estéticas" que se aplica a un Instituto de Historia del Arte todavía genera muchos malentendidos, es grato reconocer que justo ese nombre sirve bien para ampliar nuestra disciplina hacia una ciencia de la imagen. En este sentido, Anales pretende ser un medio de innovación, un órgano para presentar los logros de nuestra disciplina y de nuestro Instituto. \$\$ 